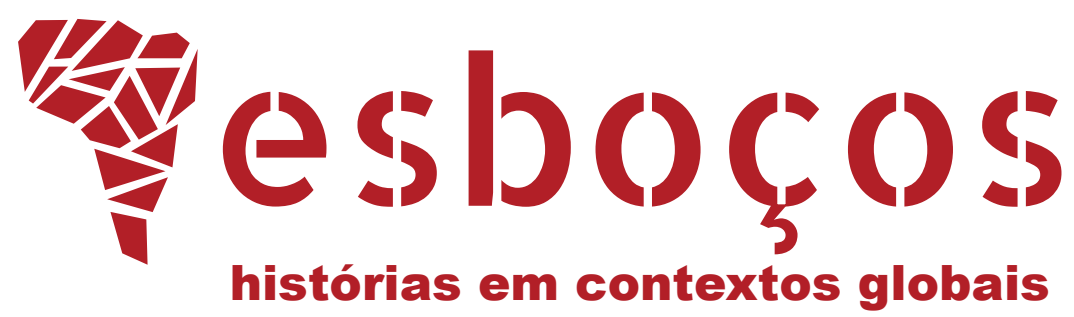

\title{
O GLOBAL E SEUS PARADOXOS: A CONSTRUÇÃO IMAGINADA DE UM CAMPO HISTORIOGRÁFICO
}

The Global and its Paradoxes: the Imagined Construction of a Historiographic Field

\section{DEBATE}

História da historiografia em perspectiva global 


\title{
RESUMO
}

Este texto é um comentário sobre o artigo de Jurandir Malerba que se publica no mesmo número de Esboços: histórias em contextos globais, em que o autor discute os paradoxos da proposição de uma história global da historiografia. Tomando como ponto de partida o conceito formulado por Benedict Anderson, de "comunidade imaginada", este artigo reflete sobre as possibilidades e os limites de imaginar a história global e a experiência coletiva da comunidade de historiadores que começa a pensar a si mesma com base nessa categoria. Dialogando com Malerba, Anderson, Jeremy Adelman, Eric Auerbach, Partha Chaterjee e outros, o ponto de chegada do texto pergunta quem está autorizado a "imaginar" a história global e, desse modo, a controlar sua narrativa. A conclusão é que a resposta a essa pergunta é inseparável da matriz de desigualdades e assimetrias que se reproduz no momento atual de produção de um mundo globalizado.

\section{PALAVRAS-CHAVE}

Historiografia. História Global. Comunidade Imaginada.

\begin{abstract}
This article comments on the piece written by Jurandir Malerba published in the current issue of Esboços: histórias em contextos globais, in which the author discusses the paradoxes of the global history of historiography. The article is based on the concept of "imagined community" proposed by Benedict Anderson, reflecting on the possibilities and limits to imagine a global history, as well as the collective experience of the community of historians who start to think about themselves through this same category. In dialogue with Malerba, Anderson, Jeremy Adelman, Eric Auerbach, Partha Chaterjee and others, this paper ends by posing the question who is authorized to "imagine" global history and, therefore, to control its narrative. The conclusion is that the answer to this question is inseparable from the matrix of inequalities and asymmetries that are reproduced in the current context of manufacturing a globalized world.
\end{abstract}

\section{KEYWORDS}

Historiography. Global History. Imagined Community. 
omunidade imaginada. Com essas palavras, que dão título a seu livro famoso publicado há bem mais de três décadas, Benedict Anderson descreveu esse artefato social de história recente, mas de uma memória que se pretende antiquíssima: a nação em sua concepção moderna (2008). A expressão, bem como cada uma das palavras que a formam, abria um horizonte de discussões inovador sobre um fenômeno central, ou uma constelação de fenômenos, que marcou as trajetórias políticas de várias partes do planeta nos últimos dois ou três séculos: a nação como problema, a consciência nacional como seu corolário e os nacionalismos como marca da sua unidade e multiplicidade de expressão ideológica e política.

A conexão entre a imaginação da Nação e a construção da disciplina da História em sua acepção "moderna" - o uso de maiúsculas e das aspas não é casual - é ponto pacífico nos estudos sobre a história da historiografia. ${ }^{1}$ A história, tal como se estabeleceu nas universidades e nos institutos históricos, sobretudo na Europa ao longo do século XIX, teve como objeto preferencial os estados nacionais - debruçou-se sobre o passado, escolheu e selecionou os antecedentes dessa formação política, imaginou sua linhagem e sua genealogia. A imaginação da nação encontrou nessa disciplina uma ferramenta poderosa de construção e legitimação. Historiadores foram atores fundamentais da imaginação da nação, definindo o enredo em que elas encontravam seu lugar, estabelecendo seus objetos de interesse, suas hierarquias de relevância.

Insistir no caráter imaginado da nação e sua história não significa afirmar que a nação e sua história são falsificações. Parafraseando Anderson, ${ }^{2}$ não há objetos falsos de história, e outros verdadeiros (o problema da falsificação propriamente dita reside em outro lugar): toda comunidade é imaginada, e todo objeto de história, também. A seleção dos aspectos do passado, dos documentos, da narrativa - todo o conjunto de operações historiográficas (CERTEAU, 1982) - é mediada pelo uso controlado da imaginação. Assim, a pergunta que importa passa a ser: como são imaginados?

Meu argumento neste artigo, comentando a reflexão de Jurandir Malerba (2019) sobre o campo emergente da história global, e da história global da historiografia em particular, deriva deste ponto de partida: para existir uma história global, ela precisa ser imaginada como tal. Como toda imaginação do gênero, ela se alimenta de aspectos da realidade, seleciona o que é relevante, hierarquiza e descarta.

Assim como historiadores não são os únicos protagonistas da construção das culturas históricas em circulação, a disciplina da história global não é tributária apenas das pesquisas acadêmicas, e as realidades "extra-historiográficas" - para usarmos uma expressão assumidamente desajeitada - também atuam no campo de forças que molda a historiografia. Historiadoras e historiadores não estão sozinhos a imaginar o "global". Eles precisam lidar com sínteses, imagens e realidades - institucionais, entre outras - produzidas por autores pertencentes a outros campos, acadêmicos ou não.

A imaginação do "global", hoje em curso, produz sua linguagem e um enquadramento, e a comunidade historiadora passa a moldar suas indagações com base nesse léxico. Conexões, processos de integração e globalização são temas que

\footnotetext{
${ }_{1}^{1}$ Para um estudo exemplar da análise dessa ligação entre nação e historiografia, debruçando-se sobre o Brasil e a obra de Francisco Adolfo de Varnhagen (1816-1878), ver o livro de Temístocles Cezar: Ser historiador no século XIX (2018).

2 Eis o comentário original: "Na verdade, qualquer comunidade maior que a aldeia primordial do contato face a face (e talvez mesmo ela) é imaginada. As comunidades se distinguem não por sua falsidade/ autenticidade, mas pelo estilo que são imaginadas" (ANDERSON, 2008, p. 33).
} 
passam a organizar a investigação e a organizar o modo como se fala dela. Não é diferente, como nos mostra Malerba, no campo da história da historiografia, movido recentemente pelo desafio de pensar a sua própria história global.

\section{UMA HISTÓRIA GLOBAL DA HISTORIOGRAFIA?}

Jurandir Malerba se apoia na leitura de sínteses produzidas por diferentes historiadores imbuídos da tarefa de pensar uma "história global" da historiografia. Mas o que há de "global" numa disciplina tão marcadamente dependente da sua relação carnal com os estados nacionais? E qual seria a relação entre a historiografia em perspectiva global e a série de historiografias nacionais que continuam a ser a marca da disciplina? Podemos falar em integração, ou o global está fadado a ser uma justaposição de historiografias mais ou menos particulares?

O artigo de Malerba lida com algumas dessas questões, debruçando-se sobre trabalhos de fôlegos distintos: obras de síntese, coletâneas, uma monografia, alguns artigos, sobretudo o livro publicado por Georg Iggers e Edward Wang em $2008,{ }^{3}$ e as obras mais recentes de Daniel Woolf (2011) sobre a história global da história. ${ }^{4}$

Trata-se de trabalhos muito diferentes. O primeiro deles, com o qual Malerba parece encontrar mais afinidade, é também o mais antigo e reúne um velho mestre da discussão historiográfica, de formação europeia e atuação no meio acadêmico norte-americano, bem como um parceiro mais jovem, sino-americano, especializado nos estudos de historiografia e história das ideias na Ásia. O segundo grupo de textos, composto pelos livros organizados e de autoria de Woolf, tem como protagonista outro empreendedor intelectual, dessa vez de extração britânica e atuação canadense, também dedicado ao estudo da história das ideias e da historiografia na longa duração.

Seguindo um caminho que Iggers já havia trilhado em trabalhos anteriores sobre a história da historiografia, a cronologia de seu trabalho em parceria com Wang é definida pela compreensão de que o moderno campo da historiografia, a despeito de se basear em tradições intelectuais muito mais antigas, começa a se articular de fato do meio para o fim do século XVIII, consolidando-se no seguinte. É um campo que se transforma sucessivamente sob a influência do nacionalismo, da profissionalização do campo e da dinâmica de configurações culturais e de debates intelectuais e políticos que moldaram seus temas e problemas até o presente. Wang soma a esse quadro um olhar informado sobre a historiografia asiática, eventualmente complementado com dados de segunda mão sobre outras tradições historiográficas que correm em paralelo.

O livro de Iggers e Wang tem como ideia central as conexões das diversas "historiografias" em várias partes do globo, sua relação com a matriz "original" (a expressão é minha) europeia e a lenta construção de um horizonte historiográfico mais ou menos comum, o qual supostamente habitamos hoje. Malerba identifica o método do livro como "comparativo", mas seu ponto central parecer residir mais numa

\footnotetext{
${ }^{3}$ Um empreendimento anterior dos dois autores imbuído do mesmo espírito sintético é a coletânea por eles organizada: Turning Points in Historiography: A Cross-Cultural Perspective (IGGERS; WANG, 2002). ${ }^{4}$ Para a tradução brasileira: Woolf (2014). Sobre o tema, Woolf acaba de publicar outra obra: A Concise History of History: Global Historiography from Antiquity to the Present (2019). A outra obra coletiva citada por Malerba é: Oxford History of Historical Writing (com Alex Schneider). Na verdade, os autores apenas organizam o $5^{\circ}$ volume dessa obra coletiva (WOOLF; SCHNEIDER, 2015).
} 
indagação sobre a convergência. Mais do que as matrizes da escrita histórica, o livro se debruça, de modo mais amplo, sobre a "cultura histórica" que se constrói e circula em escala global nos últimos dois séculos.

A história da historiografia global guarda nessa versão a marca dos processos de globalização (ou "ocidentalizações" plurais) subjacentes e compartilha das mesmas contradições. Não se trata de um processo único nem homogêneo - podemos mesmo dizer que é um campo de disputas e, por isso mesmo, dinâmico e contestado. A despeito disso, de acordo com Malerba, é um empreendimento que pretende tomar distância do eurocentrismo das análises mais comuns da historiografia.

Também sob o signo da crítica ao eurocentrismo estão construídos os trabalhos organizados e escritos por Daniel Woolf, igualmente comentados por Malerba. Centrado na história escrita pelos historiadores e comprometido a não deixar nenhuma parte do globo, nem a longa duração, de fora do seu argumento, Woolf parece mais interessado num inventário das historiografias. Reivindicando a proposta de Dipesh Chakrabarty de "provincializar a Europa", ele pretende, contudo, tratar a historiografia europeia como um caso entre outros (WOOLF, 2000). Como lggers e Wang, entretanto, o britânico também encontra nos processos de integração seu ponto de chegada, debruçando-se sobre o processo por meio do qual o "regime de historicidade" da cultura historiográfica europeia ganhou influência e se impôs ao redor do mundo a partir do século XIX.

É em torno desse caráter impositivo, ou "imperialista!!!" (o tom exclamativo é de Malerba), que parece se construir a intervenção de Woolf, reconhecendo sua importância ao mesmo tempo que tenta, de algum modo, tomar distância desse seu impulso bastante "colonizador", simultaneamente refletindo sobre as possibilidades oferecidas pelas narrativas alternativas que nascem na periferia dos processos de globalização da historiografia.

O momento contemporâneo, marcado pela "massificação" da escrita histórica e pela multiplicação de perspectivas que marcam a disciplina, é um dos pontos que Malerba declara lhe chamar a mais atenção: o paradoxo, ao menos aparente, de uma extensão transnacional da escrita histórica que segue os moldes do regime de historicidade europeu, acompanhada da fragmentação de perspectivas e temas. Faltaria apenas, segundo Malerba, incluir a própria "história global", entendida como o novo trend historiográfico, nesse quadro.

Por fim, Malerba traz para a conversa um texto recente de Jeremy Adelman, latino-americanista canadense recém-convertido a historiador global cuja reflexão sobre esse tema é utilizada para pensar, mais uma vez, as ambiguidades inerentes à emergência do "global" como categoria nos estudos históricos. Para Adelman, história global e globalização andam juntas e são mediadas pelos interesses da geopolítica presente. Daí o episódio que abre seu artigo, no qual a chanceler alemã Angela Merkel convida Jürgen Osterhammel, autor de uma monumental história "global" do século XIX, para a festa de aniversário dos seus sessenta anos. A tarefa do historiador é entreter os convidados com uma palestra sobre "o tempo e as perspectivas globais" à sombra da ascensão chinesa e da revolução tecnológica (ADELMAN, 2017). ${ }^{5}$

\footnotetext{
${ }^{5}$ O livro de Osterhammel, cuja edição original alemã é de 2009, chama-se The Transformation of the World: A Global History of the Nineteenth Century (2015) e tem 1192 páginas.
} 
A anedota é de 2014, e Adelman a conclui duvidando que Osterhammel fosse convidado agora (o artigo é de março de 2017). O retorno triunfal da retórica nacionalista e "antiglobalista" nos últimos anos teria reorganizado mais uma vez a agenda, e o convite à história global para se sentar à mesa, suspenso.

Em seu texto, Adelman faz uma breve história da emergência da "nova metanarrativa cosmopolita" que deslocou do seu lugar de proeminência a narrativa nacional anterior. A novidade nasce e se desenvolve lado a lado com os acontecimentos dos últimos trinta ou quarenta anos, como a queda do Muro de Berlim e das barreiras protetoras do capitalismo nacional, a expansão dos grandes navios porta-contentores [container shipping], a ascensão das cosmópolis e a importância crescente dos temas do ambientalismo e do aquecimento global.

Essa, no entanto, é também, e mais uma vez, uma história contraditória, que desempenhou o papel de reforçar, ao menos nos Estados Unidos, uma forma de "globalismo patriótico" que referendava o papel supostamente humanitário transnacional liderado pelo capitalismo norte-americano, reforçava o inglês como língua universal, justificava o eclipse das dinâmicas locais e nacionais na periferia do sistema em prol do protagonismo transnacional. Além disso, ao enfatizar "narrativas cosmopolitas" dos encontros entre o Ocidente e os outros, construía um "global" que refletia, antes de mais nada, uma narrativa unilateral e reconfortante - ao menos do ponto de vista dos vitoriosos da globalização -, focada nos encontros promissores entre os diferentes e na curiosidade simpática (ou condescendente) com os vizinhos mais ou menos distantes. ${ }^{6}$

Diante desse retrato pouco edificante da história global, não é de estranhar, diz Adelman, que a reação às narrativas cosmopolitas pós-nacionais tenha sido grande e marcada por forte ceticismo quanto às intenções da história global em primeiro lugar. Há aqui um paralelo entre a história dos historiadores e a retórica emergente do "antiglobalismo", marcada por "histórias profundas' de ressentimento" fundadas na perda ou na ameaça a liames afetivos e materiais locais, desconfiada da política feita a portas fechadas por atores políticos e econômicos distantes e desconectados, justificando suas decisões políticas com a linguagem alienante dos mercados, transitando nos circuitos transnacionais cuja lógica e sentido escapam inteiramente à vida cotidiana das pessoas comuns, mas insistindo no caráter intrinsecamente positivo da integração e da convergência global.

É interessante chamar a atenção aqui para um aspecto da narrativa de Jeremy Adelman que Malerba não aborda em seu artigo-comentário. Como o historiador canadense nos recorda em seu texto, durante anos, ele foi responsável por supervisionar a área de internacionalização acadêmica na Universidade de Princeton. Como outras pertencentes ao quadro seleto de instituições acadêmicas de elite norte-americanas, como Columbia University e New York University - que abriram seus escritórios internacionais em lugares como Dubai, Pequim e Rio de Janeiro -, Princeton também investiu na criação de "cadeias globais de fornecimento de conhecimento".

"Nunca ocorreu, a mim ou a outros, perguntar: o que iria acontecer com aquelas escalas mais modestas, menos sexy, de engajamento cívico?", confessa Adelman. "Não dávamos atenção a isso. Tratava-se apenas de restos de provincialismo,

\footnotetext{
${ }^{6} \mathrm{Na}$ verdade, entre os "Westerners" e os "Resteners", replicando o trocadilho intraduzível que brinca que a história global seria a soma das histórias do "West" (do "Ocidente") e do "Rest" (do "resto").
} 
conduzidos silenciosamente para fora do palco sobre o qual em tese deveríamos estar educando o novo homo globus". Seu artigo aparece, assim, também como um momento de tomada de consciência, reorientação do projeto, ou mea-culpa.

Claro que o rebote do provincialismo teve seu preço, em tempos de Brexit, Trump, Orban e outros tantos campeões tão ou mais medíocres do "antiglobalismo" que fazem paradoxalmente parte de um fenômeno de escala global.

A despeito de tudo, as conclusões de Adelman, que Jurandir Malerba também ecoa em seu artigo, são uma chamada à correção de rumo. Não se trata de cair na tentação de ceder ao ressentimento dos provincialismos, é claro, mas de aceitar o desafio de construir, em suas palavras, "narrativas da vida global que levem em consideração a desintegração na mesma medida em que a integração, os custos, e não apenas as recompensas, da interdependência". Isso implica, de algum modo, ouvir as outras vozes dessa narrativa da globalização, mesmo que elas sejam dissonantes - afinal, também fazem parte das "histórias profundas das transformações globais".

Em outras palavras, se uma história global deve ser feita, não pode ser só uma história de integração e cosmopolitismo, mas sim - e talvez sobretudo - uma história das desigualdades e das assimetrias, das resistências a esses mesmos processos.

\section{A IMAGINAÇÃO HISTÓRICA DO GLOBAL}

Talvez seja inútil se perguntar se o "global" é uma categoria realmente relevante para a pesquisa histórica. A palavra está aí, circula, se prende aos objetos e é utilizada para descrever realidades novas e antigas; faz parte do vocabulário contemporâneo e se multiplica - globalização, mercados globais, aquecimento global etc. Mesmo que disputemos o sentido e a relevância do conceito, não se pode negar sua crescente presença na linguagem contemporânea, o que, por si mesmo, se impõe à análise. A questão não é denunciar o global como uma falsificação, mas compreender como a emergência do "global" como categoria só faz sentido por ser correlata à imaginação do globo como um espaço "comunitário".

Quem lê este artigo pode, de maneira justificada, torcer o nariz ao deparar com uma palavra que remeta à ideia de "comunidade" associada aos processos de integração violenta e desigual em curso que tomam às vezes o nome de globalização. Em contraste, a imagem "comunitária" parece sugerir aquela mesma ideia de "encontro feliz entre diferentes" que Adelman e Malerba muito rechaçaram. Mas a intenção aqui é resgatar a palavra no sentido com o qual Benedict Anderson utiliza no livro que citei no início deste texto. A analogia entre a nação e o espaço global é o ponto de partida aqui. Vou sugerir que essa associação não seja uma questão nova.

Não é só a ideia de nação que se cria no século XIX para pensar as relações anônimas e verticais que integravam, numa mesma construção imaginada, pessoas que jamais se viram face a face. A história "formal e acadêmica" em sua versão moderna nasce simultaneamente, desempenhando um papel semelhante e complementar. Como aponta Carolyn Steedman (2018, p. 10), a história desempenha o papel de fornecer a maior parte do material pelo qual lembramos, individual ou coletivamente, coisas com as quais não temos nenhuma experiência direta. Ela não só inscreve fatos, acontecimentos, gestas individuais e coletivas na grande narrativa nacional, mas também nos grandes movimentos "tectônicos" de consolidação de estados, definição de soberanias territoriais, conexões e conquistas transcontinentais. 
Como lembra Anderson, isso que a ideia de nação tentava capturar utilizando imagens de unidade cultural e linguística traduzia também, no plano material, uma crescente inter-relação econômica, fornecida pelo mercado capitalista em expansão na aurora da industrialização. De acordo com Anderson (2008, p. 78), o que tornou possível "imaginar" as novas comunidades nacionais foi exatamente a combinação, "mais ou menos casual, porém explosiva, entre um modo de produção e relações de produção (o capitalismo), uma tecnologia de comunicação (a imprensa) e a fatalidade da diversidade linguística humana". Assim, um dos aspectos mais intensamente contraditórios desse processo de constituição da ideia de nação é que ela não se opunha à expansão das conexões globais que o próprio capitalismo produziu, mas, ao contrário, era tornada possível por ela.

Hegel, no início do século XIX, capturou a emergência dessa interconexão com a imagem de um "sistema de necessidades" - a crescente interdependência que fazia com que cada pedaço do globo passasse a se conectar a todos os outros por uma rede de dependências mútuas e na qual o consumo e o bem-estar de um lado do planeta passava a depender cada vez mais do trabalho e dos recursos que existiam do outro lado. O sistema de necessidades, uma ideia que Hegel formulou com base nas suas leituras de Adam Smith, estava na origem da ideia hegeliana da história universal, que expressava a consciência historiográfica - portanto, a autoconsciência - da interconexão global que começava a aparecer como inexorável na aurora do capitalismo industrial (BUCK-MORSS, 2005).

Hegel celebrava esse novo estado de coisas, pois seria a expressão material da inevitável conexão espiritual cujo desvelamento no tempo era a chave de compreensão do sentido da história (HEGEL, 2007). Seu contemporâneo, Goethe, diante da revolução da imprensa que, pela primeira vez, permitia que os textos europeus chegassem a todo o mundo, traduzidos nas diversas línguas nacionais - mas também fazia com que textos chineses, persas e sérvios pudessem ser lidos por um europeu como ele -, celebrava a chegada de um tempo em que uma "literatura mundial" (Weltliteratur) se constituiria (AUERBACH, 2007, p. 357-374).

O entusiasmo de Goethe, mais até do que o de Hegel, é sintomático. O grande autor, que define quase de modo paradigmático a literatura nacional alemã no século XIX, enxergava a emergência das literaturas nacionais como um fenômeno eminentemente mundial, marcado pela mútua fecundação de elementos diversos.

A historiografia nacional parece não ter nascido sob o mesmo signo "cosmopolita". Ao contrário da literatura nacional, cuja marcante pluralidade era celebrada por Goethe, o modelo de história nacional que se desenvolveu ao longo do século XIX estava menos interessado no papel fecundador da diversidade do que na celebração da singularidade nacional (CEZAR, 2018). O reconhecimento das distintas narrativas nacionais, e mesmo da sua eventual conexão histórica - no caso das nações europeias -, servia antes de tudo para marcar a divergência inevitável e a eventual superioridade moral - eventualmente, política e militar - que brotava dessa diferença e que se acentuava na competição entre essas nações na "era dos Impérios".

Se a história apareceu primeiro como modo de pensar e como tópico de estudo na academia, em seguida se tornou também um conjunto básico de informações a serem ensinadas a todas as crianças que passavam pelos sistemas nacionais de educação pública implantados na Europa no século XIX. A cultura histórica que se integrou assim à imaginação coletiva da nação também a tornou "emocionalmente plausível". O caráter imaginado desse processo é evidente, mas é sobretudo na sua 
articulação com a dominação colonial que os limites fluidos entre a imaginação e o delírio aparecem com força. O caráter arbitrário e impositivo desse processo mostra todo o seu alcance, como quando os professores franceses de história ensinavam aos seus alunos, nas escolas coloniais do Senegal ou da Costa do Marfim, a gesta dos "nossos" ancestrais: os gauleses (BINET, 1967).

Entrelaçada a esse sistema assimétrico das necessidades em escala mundial, a historiografia nacional parece ter a missão de reforçar as posições desiguais que as nações ocupavam nesse sistema, alimentando ao mesmo tempo a competição pela posição de proeminência num sistema de hierarquias geopolíticas. Serviu do mesmo modo como ferramenta ideológica de colonização e arma nas disputas entre as potências coloniais. As narrativas de singularidade, ou destino manifesto, se articularam com as histórias evolucionistas sobre a missão civilizadora ocidental ou da supremacia branca. Mesmo com o reconhecimento da variedade histórica das civilizações do globo, somente à história europeia se conferia o papel de promover uma síntese que englobasse e desse sentido às histórias particulares dos povos periféricos ou conquistados. ${ }^{7}$

O que extraímos disso tudo é que a consciência nacional e seu correlato historiográfico já nasceram tanto sob o signo da multiplicidade quanto da violenta desigualdade. Se quisermos pensar algo sobre o futuro de uma narrativa historiográfica com ambições globais, é preciso refletir acerca das consequências disso.

O modelo nacional europeu nasceu, de acordo com Anderson, da "destilação espontânea do 'cruzamento' complexo de diferentes forças históricas". Mas depois que foram criados, esses modelos políticos e institucionais, bem como todos os produtos culturais correspondentes, se tornam "modulares" e capazes de ser transplantados para uma grande variedade de terrenos sociais, a fim de se incorporar e ser incorporados a uma variedade igualmente grande de constelações políticas e ideológicas (ANDERSON, 2008, p. 30). O modelo nacional e a consciência histórica de tipo nacional se tornam artefatos globais por excelência, introduzidos e circulando nos vários contextos que, sobretudo nos espaços coloniais e pós-coloniais, se apropriam deles como modelos.

Partha Chaterjee (2000), revisitando o argumento de Anderson, coloca em dúvida o papel passivo que os povos colonizados tiveram ao absorver a imagem "modular" da nação criada nas metrópoles europeias. Se a nação como artefato (ou produto) cultural apresenta esse caráter impositivo, o que restaria para as novas nações "imaginarem"?

Podemos tomar essa observação de Chaterjee como álibi para voltar à nossa tarefa de engajar os pontos que Malerba expõe em seu argumento a respeito da história da historiografia em perspectiva global. Para dizer claramente, a emergência paralela da história global como campo historiográfico e da globalização como categoria geopolítica apresenta analogias e diferenças importantes com os processos que constituíram as consciências nacionais e suas historiografias correspondentes.

\footnotetext{
7 O melhor exemplo continua sendo Hegel (2007), leitor ávido de narrativas sobre a África e a Ásia, marcadas pelo orientalismo, que, em suas aulas sobre a filosofia da história em Berlim, chegava a afirmar que a África não tinha história porque não apresentava consciência histórica. O "paradigma hegeliano da história da África" apenas reconhecia a historicidade africana a partir do colonialismo europeu.
} 
Por um lado, a nação foi e é imaginada como "intrinsecamente limitada", definida pela soberania territorial e, também devido à mencionada "fatalidade linguística" (e os processos de homogeneização linguística que se seguiram), ambicionava estabelecer claramente quem estava dentro e quem estava fora, isto é, quem tinha o direito de pertencimento à comunidade política. Por outro lado, vale apontar que a imaginação contemporânea do "global", em suas distintas versões políticas, aponta para o contrário: o que o global pode conter é intrinsecamente ilimitado, apontando para a ausência de fronteiras e para a própria diluição das ideias de território e soberania.

O global, todavia, não abole a diferença; ao contrário, intensifica-a. A aparente emergência do inglês como língua franca, por exemplo, é uma demonstração adicional de como a fatalidade linguística continua a desempenhar um papel ao desenhar quem pode ou pode participar dessa cidadania global, e como. Outras "fatalidades" (mas poderíamos chamar de contingências violentamente construídas), também: $O$ lugar de nascimento, mais do que qualquer outra variável particular, continua a ser o indicador mais relevante para prever a expectativa sobre a qualidade de vida de um indivíduo e do que pode almejar na hierarquia geopolítica planetária.

A contarmos com o relato de Malerba sobre a disseminação do regime de historicidade europeu pelo globo, parece claro que a historiografia repete as assimetrias dos processos de globalização corrente e contém contradições semelhantes. Relações de força assimétricas moldam o campo e fornecem os materiais conflitantes sobre o qual o global é imaginado não só como categoria, mas como realidade circundante. O "sistema de necessidades" tem sua contrapartida na articulação das narrativas históricas e nas conexões assimétricas que Malerba recupera no debate sobre a "ocidentalização" - "múltipla, diversa", mas também contestada e marcada por apropriações seletivas.

\section{CONSIDERAÇÕES FINAIS: QUEM CONTROLA A NARRATIVA GLOBAL? ALGUMAS DÚVIDAS SOBRE $O$ FUTURO DA HISTORIOGRAFIA}

No imediato pós-guerra, o filólogo alemão Eric Auerbach, num artigo famoso, perguntava o significado que poderia ainda ter o conceito goethiano de Weltliterature. Para Auerbach, "nossa terra vinha se tornando cada vez menor e perdendo sua diversidade"; a imagem da literatura mundial como o resultado do "intercurso frutífero" entre os membros da humanidade, na versão otimista de Goethe, perdia seu ímpeto diante das forças que impunham lentamente a uniformidade e a extinção das tradições individuais. A humanidade, dizia Auerbach, estava se tornando "padronizada". 8

O diagnóstico parece contraditório. Como nós hoje, Auerbach havia testemunhado a emergência violenta dos particularismos nacionalistas e do chauvinismo mais radical, e já escrevia sob a consciência da Guerra Fria. Mas

\footnotetext{
${ }^{8} \mathrm{O}$ artigo foi publicado originalmente na Suíça (MUSCHG; STAIGER, 1952). Foi traduzido do alemão para o inglês por Maire e Edward Said e publicado com o título "Philology and Weltliteratur" (AUERBACH, 1969). A edição brasileira, que consultei junto da edição em inglês, foi publicada em 2007.
} 
mesmo reconhecendo isso, Auerbach insistia: ainda que contrastantes, as diferentes "vontades nacionais" defendiam, ao fim e ao cabo, os "mesmos padrões e formas para a vida moderna". O prognóstico, ao menos na minha opinião, é um tanto sombrio.

Caso a humanidade tenha sucesso em sustentar o choque de um processo tão poderoso e rápido de concentração - para a qual sua preparação espiritual vem sendo pobre - então o homem terá que acostumar-se à existência em um mundo padronizado, a uma única cultura literária, apenas um punhado de linguagens, e talvez mesmo a apenas uma única linguagem literária. E com isso, a noção de Weltliteratur irá finalmente e ao mesmo tempo ser realizada e destruída (AUERBACH, 2007, p. 358).

Quase setenta anos nos separam dessas linhas, e podemos nos perguntar quanto das previsões de Auerbach se concretizaram. Ao olharmos para fora da janela, o que vemos nos oferece indícios contraditórios. Por um lado, objetos, gostos e formas culturais "globais" são oferecidos em cada esquina; é possível tomar um café expresso em Nova Délhi que se parece em tudo com aquele que tomamos em São Paulo e talvez num estabelecimento com o mesmo nome daquele que encontramos em Nova York. Por outro lado, a imagem de uma "aldeia global" é enfatizada pela oferta de produtos "exclusivos", "étnicos", produzidos por artesãos "autênticos" em aldeias remotas em lugares supostamente exóticos, com materiais e técnicas locais e ancestrais, comerciados sob os auspícios do fair trade nas prateleiras e nas vitrines do globo.

Em contraste, o lámen industrializado produzido por uma multinacional suíça pode ser comprado de um vendedor de rua numa aldeia aos pés do Himalaia, oferecido no sabor masala, criteriosamente misturado e empacotado na fábrica europeia de acordo com a "receita" indiana. O mercado global se oferece simultaneamente como o lugar em que a diversidade é celebrada, transformando-se em uma mercadoria que circula por caminhos estritamente padronizados e controlados por um número extraordinariamente limitado de empresas transnacionais.

Ainda que frequentemente tratado com autônomo e refratário à lógica mercadológica do consumo material e cultural, o campo intelectual do qual a historiografia faz parte tem uma lógica própria que, entretanto, não pode se imunizar completamente das dinâmicas atuais da globalização, com sua mistura contraditória de homogeneização e celebração da heterogeneidade. Assim como no processo corrente de valorização das literaturas africanas e asiáticas, que passam a ser consumidas e circulam nas mesmas cadeias de produção e legitimação cultural que antes haviam consagrado o cânone literário europeu, vimos também no campo das ciências humanas processos análogos que se desenvolveram nas últimas duas décadas.

Nas academias norte-americanas e europeias, os estudos subalternos e pós-coloniais se juntaram aos campos emergentes e críticos dos estudos de gênero e das relações raciais para configurar um novo quadro de reflexão sobre a realidade social que é fortemente marcado pela crítica à homogeneização e à adoção acrítica de categorias e teorias produzidas pelo "centro". A chamada a "provincializar a Europa" e a descentrar as formas de conhecimento "ocidentais" e seus "paradigmas 
racionalistas e normativos" em favor das "epistemologias do sul" desafia a ideia de que há categorias e formas de pensamento "universais". ${ }^{9}$

Essas mesmas teorias críticas ganham força e visibilidade, entretanto, ao reverberarem em escala transnacional por meio das mesmas caixas de ressonância intelectual que haviam consagrado os maitres-à-penser europeus, igualmente inovadores e iconoclastas décadas antes. A historiografia em chave "global" segue rigorosamente os mesmos caminhos de difusão e afirmação, e passa a enveredar-se por todos os lugares do "sul global" seguindo um padrão notavelmente homogêneo.

Não se trata de denunciar como engodo ou moda passageira as transformações que se operam no campo intelectual. Uma comunidade intelectual também é imaginada, com métodos e materiais à sua disposição, e não pode fugir completamente, por mais que queira, à lógica dos processos anônimos da qual é parte. A história da historiografia, esse exercício de autoexame que permite à comunidade de historiadores se debruçar sobre os próprios procedimentos e produzir uma narrativa sobre a própria trajetória passada e desenhar um futuro possível, é produto da interação entre os contextos em que historiadores e historiadoras escrevem suas histórias e os próprios engajamentos intelectuais e políticos.

Como nos lembra a discussão levantada por Jurandir Malerba (2019), a história global e a história da historiografia em perspectiva global refletem as contradições inerentes desses processos: por um lado, o reconhecimento da impossibilidade de pensar histórias exclusivamente locais; por outro, a rejeição peremptória de uma narrativa global unificada que cancele as dinâmicas nacionais, locais e translocais, ignorando o campo de disputas em que todas essas discussões se tornam possíveis. A crítica à pretensão de universalidade do regime de historicidade europeu, segundo Jurandir Malerba, se soma à descoberta de que talvez a narrativa de que a "autoconsciência histórica das sociedades" - e mesmo a história como "atividade acadêmica" - tenha nascido na Europa e se espalhado por todo o mundo seja, se não completamente equivocada, ao menos parcial e insuficiente.

Nem o "Ocidente" é um lugar homogêneo nem sua pretensão de "universalidade" é tão exclusiva. A reivindicação de modelos alternativos dessa história teria, assim, um impacto potencial profundo na imaginação de uma "história global da historiografia". ${ }^{10}$

O impasse que se coloca aqui, para a história da historiografia e para a história global como um todo, é claro. Não há provavelmente uma resposta única às perguntas impostas pelo momento atual, em que o "global" ganha força. Mas essa configuração, como tantas outras antes, é também contingente. Assim como a "nação" e o "nacional", o "global" não tem contornos necessários e indisputáveis, talvez nem tenha um conteúdo predefinido. A disputa sobre seu significado no campo da historiografia reflete os conflitos mais gerais acerca do significado e da direção dos processos históricos que tenta captar.

Mas o problema apontado antes, quando lembrava de Partha Chaterjee, persiste no campo que queremos discutir. Quem, afinal de contas, está credenciado

\footnotetext{
${ }^{9}$ Para uma discussão acerca dessas questões, refletidas sobre o caso da historiografia indiana, ver Chakrabarty (2015).

${ }^{10}$ Para uma discussão muito abrangente e aguda sobre essas questões, que certamente mereceriam atenção para uma leitura mais aprofundada sobre os temas que Malerba levanta, ver Santos, Nicodemo e Pereira (2017). Agradeço a Rodrigo Bonaldo pela indicação.
} 
para "imaginar" o global? E, portanto, quem pode controlar a narrativa que se produz sobre ele? É notável, mesmo que não seja surpreendente, que, ao menos por enquanto, quem parece tomar frente no controle dessa narrativa - por mais multicultural que se apresente - sejam os atores sociais que ocupam hoje as mesmas posições institucionais de privilégio na produção e na circulação de conhecimento que ocuparam outrora aqueles responsáveis por controlar a narrativa que se quer superar.

Para nós, o paradoxo é este: se o preço da participação no "global" é continuarmos ocupando o papel de fornecedores dos relatos parciais que serão depois processados nas grandes narrativas de síntese, o que sobra para imaginarmos?

\section{REFERÊNCIAS}

ADELMAN, Jeremy. What is global history now? Aeon, 2 March, 2017. Disponível em: https://aeon.co/essays/is-global-history-still-possible-or-has-it-had-its-moment. Acesso em: 24 de jun. de 2019.

ANDERSON, Benedict. Comunidades imaginadas: reflexões sobre a origem e a difusão do nacionalismo. $2^{\mathrm{a}}$ edição. São Paulo: Companhia das Letras, 2008.

AUERBACH, Erich. Philology and Weltliteratur. The Centennial Review, East Lansing, v. 13, n. 1, p. 1-17, Winter 1969.

AUERBACH, Erich. Ensaios de literatura ocidental. São Paulo: Duas Cidades/Editora 34, 2007.

CHATERJEE, P. Comunidade imaginada por quem? In: BALAKRISCHNAN, Gopal (ed.) Um mapa da questão nacional. Rio de Janeiro: Contraponto, 2000, p. 227-238.

BINET, François. L'Histoire africaine et nos ancêtres les gaulois, Revue Française d'Histoire d'Outre-Mer, Paris, t. LIV, n. 194-197, 1967, p. 209-218.

BUCK-MORSS, Susan. Hegel, Haiti and Universal History. Pittsburgh: University of Pittsburgh Press, 2009.

CEZAR, Temístocles. Ser historiador no século XIX: o caso Varnhagen. Belo Horizonte: Autêntica, 2018.

CHAKRABARTY, Dipesh. Provincializing Europe: Postcolonial Thought and Political Difference. Princeton: Princeton University Press, 2000.

CHAKRABARTY, Dipesh. The Calling of History: Sir Jadunath Sarkar and His Empire of Truth. Chicago: University of Chicago Press, 2015.

CERTEAU, Michel. A escrita da história. Rio de Janeiro: Forense Universitária, 1982.

HEGEL, Georg W. F. A razão na história. Lisboa: Edições 70, 2007. 
IGGERS, Georg G.; WANG, Q. Edward (com assistência de Supriya Mukherjee). A Global History of Modern Historiography. New York: Routledge, 2013.

IGGERS, Georg G.; WANG, Q. Edward (ed.).Turning Points in Historiography: a Cross-Cultural Perspective. New York: The University of Rochester Press, 2002.

MALERBA, Jurandir. História da historiografia e perspectiva global: um diálogo possível?. Esboços, Florianópolis, v. 26, n. 43, p. 457-472, set./dez. 2019.

MUSCHG, Walter; STAIGER, Emil (ed.) Weltliteratur: Festgabe für Fritz Strich zum 70. Geburtag. Berna: Franke Verlag, 1952.

OSTERHAMMEL, Jürgen. The Transformation of the World: a Global History of the Nineteenth Century. Princeton: Princeton University Press, 2015.

SANTOS, Pedro Afonso Cristovão dos; NICODEMO, Thiago Lima; PEREIRA, Mateus Henrique de Faria. Historiografias periféricas em perspectiva global ou transnacional: eurocentrismo em questão. Estudos Históricos, Rio de Janeiro, v. 30, n. 60, p. 161-186, jan.-abr. 2017.

STEEDMAN, Carolyn. Poetry for Historians: Or, W.D. Auden and History.

Manchester: University of Manchester Press, 2018.

WOOLF, Daniel. A Global History of History. Cambridge: Cambridge University Press, 2011.

WOOLF, Daniel. Uma história global da história. Petrópolis: Vozes, 2014.

WOOLF, Daniel; SCHNEIDER, Alex (ed.). Oxford History of Historical Writing. Volume V: Historical Writing since 1945. Oxford: Oxford University Press, 2015.

WOOLF, Daniel. A Concise History of History: Global Historiography from Antiquity to the Present. Cambridge: Cambridge University Press, 2019.

\title{
NOTAS
}

\author{
AUTORIA \\ Henrique Espada Lima: Doutor. Professor associado, Universidade Federal de Santa Catarina, Centro \\ de Filosofia e Ciências Humanas, Departamento de História, Florianópolis, SC, Brasil \\ ENDEREÇO PARA CORRESPONDÊNCIA \\ Rua Jerônimo José Dias, 102, 88045-100, Florianópolis, SC, Brasil.

\section{AGRADECIMENTOS} \\ Gostaria de agradecer à equipe editorial de Esboços pelo convite para participar nesta seção. \\ Agradeço também a Rodrigo Bonaldo pelos comentários e as indicações bibliográficas, que tentei \\ incorporar pontualmente.
}




\section{FINANCIAMENTO}

Este artigo foi financiado com bolsa de Produtividade em Pesquisa do Conselho Nacional de Desenvolvimento Científico e Tecnológico (CNPq).

\section{APROVAÇÃO DE COMITÊ DE ÉTICA EM PESQUISA}

Não se aplica.

\section{CONFLITO DE INTERESSES}

Não houve conflito de interesses.

\section{LICENÇA DE USO}

Este artigo está licenciado sob a Licença Creative Commons CC-BY. Com essa licença você pode compartilhar, adaptar, criar para qualquer fim, desde que atribua a autoria da obra.

\section{PUBLISHER}

Universidade Federal de Santa Catarina. Programa de Pós-Graduação em História. Portal de Periódicos UFSC. As ideias expressadas neste artigo são de responsabilidade de seus autores, não representando, necessariamente, a opinião dos editores ou da universidade.

\section{EDITORES}

Alex Degan

Beatriz Mamigonian

Fábio Augusto Morales

Flávia Florentino Varella (Editora-chefe)

Tiago Kramer de Oliveira

Waldomiro Lourenço da Silva Júnior

\section{HISTÓRICO}

Recebido em: 15 de julho de 2019

Aprovado em: 28 de agosto de 2019

Como citar: LIMA, Henrique Espada. O global e seus paradoxos: a construção imaginada de um campo historiográfico. Esboços, Florianópolis, v. 26, n. 43, p. 486-500, set./dez. 2019. 